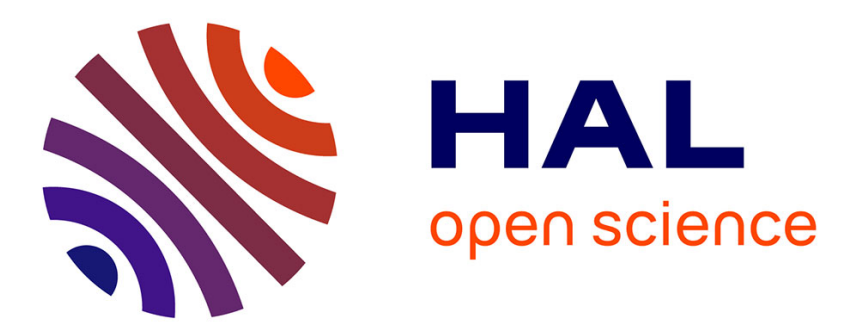

\title{
Complete post-synthetic modification of a spin crossover complex
}

\author{
Alejandro Enriquez-Cabrera, Lucie Routaboul, Lionel Salmon, Azzedine \\ Bousseksou
}

\section{- To cite this version:}

Alejandro Enriquez-Cabrera, Lucie Routaboul, Lionel Salmon, Azzedine Bousseksou. Complete postsynthetic modification of a spin crossover complex. Dalton Transactions, 2019, 48 (45), pp.1685316856. 10.1039/c9dt03587g . hal-02570013

\section{HAL Id: hal-02570013 \\ https://hal.science/hal-02570013}

Submitted on 23 Nov 2020

HAL is a multi-disciplinary open access archive for the deposit and dissemination of scientific research documents, whether they are published or not. The documents may come from teaching and research institutions in France or abroad, or from public or private research centers.
L'archive ouverte pluridisciplinaire HAL, est destinée au dépôt et à la diffusion de documents scientifiques de niveau recherche, publiés ou non, émanant des établissements d'enseignement et de recherche français ou étrangers, des laboratoires publics ou privés. 


\title{
Complete post-synthetic modification of a Spin Crossover complex
}

\author{
Alejandro Enríquez-Cabrera, Lucie Routaboul, Lionel Salmon*and Azzedine Bousseksou*
}

Received 00th January 20xx, Accepted 00th January 20xx

DOI: $10.1039 / x 0 x \times 00000 x$

The post-synthetic reaction between $p$-anisaldehyde and the spincrossover compound $\left[\mathrm{Fe}\left(\mathrm{NH}_{2}-\mathrm{trz}\right)_{3}\right]\left(\mathrm{NO}_{3}\right)_{2}$ was explored, obtaining different degrees of transformation from $23 \%$ to a full conversion varying the reaction time. The post-synthetic SCO complexes obtained, were studied by magnetometry, powder X-ray diffraction (PXRD), elemental analysis, solid state NMR and IR and compared with the corresponding compound obtained by direct synthetic routes, revealing new spin crossover properties.

SCO materials have attracted much attention in the past few years due to their integration into different devices ${ }^{1}$ for different applications in photonics, ${ }^{2}$ electronics ${ }^{3,4}$ and mechanics. ${ }^{5}$ In order to go towards such applications, specific SCO behaviour or transition temperatures are expected while a particular attention is paid to their nanostructuration. 6,7 The post-synthetic modification (PSM) carrying out chemical transformation or exchange on pre-synthesised materials has emerged as a powerful strategy to introduce functionality without affecting the original structure. In particular, such method has proven to be very useful in the recent development of metal-organic frameworks (MOFs) ${ }^{8}$ or biomolecules ${ }^{9}$ and therefore it could be a good approach in the development of new SCO materials.

Only few reports concern PSM and spin crossover material, and deal with the functionalization of 3D Hofmann clathrate MOF$^{10}$ or chains-like iron-triazole complexes ${ }^{11,12}$ and more recently of a dinuclear iron(III) complex ${ }^{13}$ and Fe" $\left[\mathrm{M}^{\mathrm{IV}}(\mathrm{CN})_{8}\right]^{4-}(\mathrm{M}$ $=\mathrm{Mo}, \mathrm{Nb}$ ) cyanido-Bridged Frameworks. ${ }^{14}$ To the best of our knowledge, no complete reaction has been reported in spite of stoichiometric conditions. Wang et al. recently ${ }^{11,12}$ reported a post-synthetic procedure in which they obtain up to $15 \%$ chemical transformation in the final iron-triazole complex, leading to a slight increase of the spin crossover temperature and new luminescence properties.

LCC, CNRS, 205 route de Narbonne, 31077 Toulouse, France. E-mail: lionel.salmon@lcc-toulouse.fr

† Footnotes relating to the title and/or authors should appear here.

Electronic Supplementary Information (ESI) available. See DOI: 10.1039/x0xx00000x

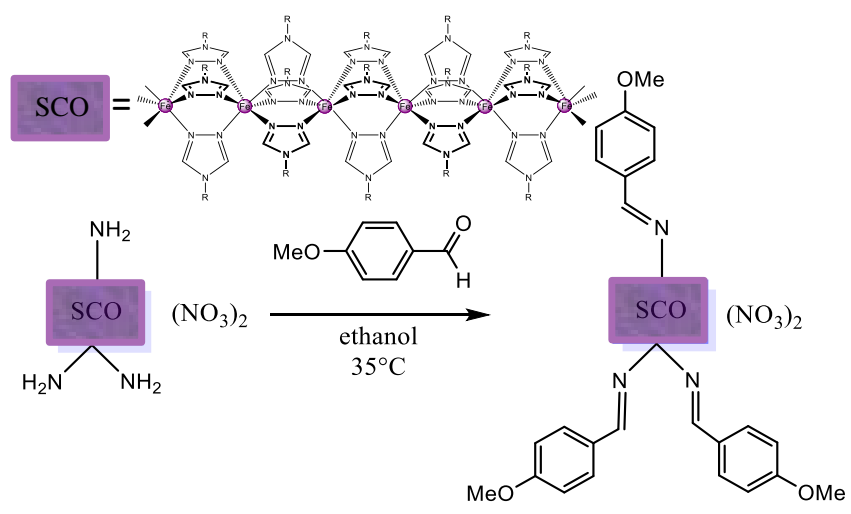

Scheme 1 Post-synthetic reaction using $p$-anisaldehyde.

In the present paper, we wanted to demonstrate that this post chemical transformation can be fully achieved and can generate spin crossover compounds whose physical properties can be different in comparison with the corresponding complex synthesized by direct methods, opening the way towards new routes for SCO materials.

In order to integrate such materials into devices it is necessary that they have a transition above room temperature, for which we started with the complex $\left[\mathrm{Fe}\left(\mathrm{NH}_{2}-\mathrm{trz}\right)_{3}\right]\left(\mathrm{NO}_{3}\right)_{2}(1$ with $\mathrm{NH}_{2}$-trz $=4$-amino-1,2,4-triazole) that in our case has a $\mathrm{T}_{1 / 2} \uparrow=308 \mathrm{~K}$ and $\mathrm{T}_{1 / 2} \downarrow=338 \mathrm{~K}$. According to the experimental conditions (see ESI), the post-synthetic methodology developed in this work consists to form a Schiff base by reaction of 1 with $p$-anisaldehyde using $12 \mathrm{eq}$ in ethanol at $35^{\circ} \mathrm{C}$ during increasing time: $3 \mathrm{~h}(2), 6 \mathrm{~h} \mathrm{(3),} 12 \mathrm{~h} \mathrm{(4)}$ and $72 \mathrm{~h}(5)$. The final products were analysed by $I R$ to confirm the presence of the imine by its signature peak at $1604 \mathrm{~cm}^{-1}(\mathrm{C}=\mathrm{N})$, and the amount of substitution was determined by elementary analyses resulting in $23.2 \%(2), 58.6 \%(3), 78.5 \%(4)$ and $100 \%(5)$. It is interesting to notice that an analogous functionalization reaction in 1,2dichloroethane was unsuccessful, leading instead to decomposition/oxidation of the coordination polymer. This shows that choice of solvent is an important factor in the postsynthetic reaction. 
We synthesized also the corresponding imino complex by direct synthesis (DS) starting from the imino ligand (see ESI) in order to compare its properties with those of the post-synthetic imino complex. It is well known that the SCO behaviour is strongly dependent of different structural factors such as crystallinity ${ }^{15}$ or polymorphism. ${ }^{16}$ Interestingly, we found that in contrast with the post synthetic reaction, the direct synthesis of the imino complex when carried out in the normal stirring conditions, resulted systematically in an amorphous powder (6); it was necessary to use a solvent diffusion technique in order to obtain a crystalline powder (7) as shown in figure 1 , this is important in order to make a fair structure-properties relationship.

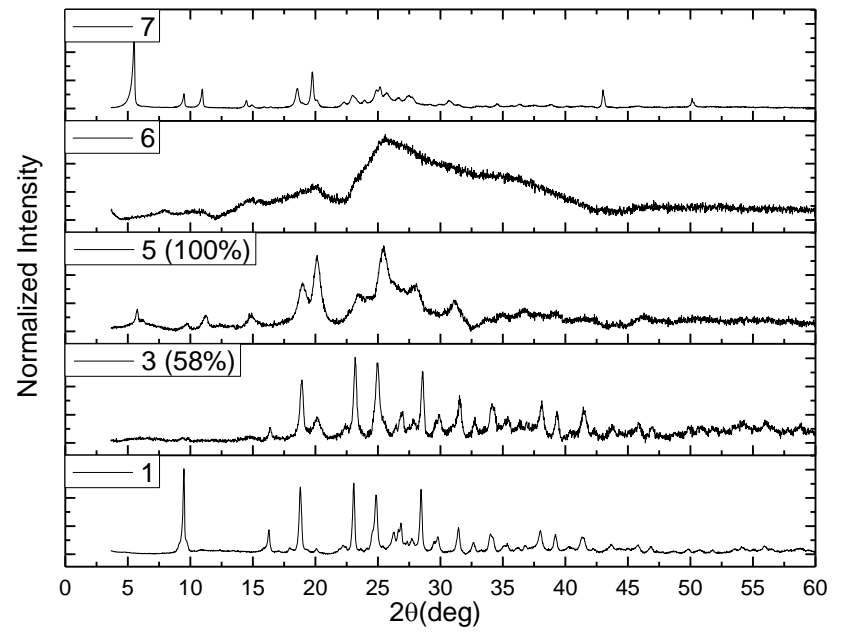

Fig. 1. Powder X-ray diffractrogram for sample 1, 3, 5, 6 and $\mathbf{7}$

The PXRD data for the post-synthetic samples (see ESI) reveal that the structure changes while increasing the amount of imine; at $23 \%$, the diffractogram remains nearly the same as that of the amino derivative, while for higher transformations, we can clearly see an additional diffraction pattern. In fact, as considered by Wang et al.; ${ }^{12}$ the retention of the structure is obtained for a weak substitution, which could be considered as grafting. It is interesting to notice that such behaviour is in contrast with that obtained for the $\left[\mathrm{Fe}(\mathrm{Htrz})_{2}(\operatorname{trz})\right]\left(\mathrm{BF}_{4}\right)$ derivative for which a drastic modification of the structure was observed for only $3 \%$ substitution of the triazole ligand by the aminotriazole one. ${ }^{17}$ In the latter case, the effect on the crystal lattice was attributed by a reorganization of the interactions between the Fe-triazole chains, which are directly linked through $\mathrm{N}-\mathrm{H} \cdots \mathrm{N}$ interactions involving $\mathrm{Htrz}$ and trz- ligands in the pristine compound. ${ }^{18}$ Finally, in the present case, when $100 \%$ substitution is achieved the structure is completely modified and is similar to that obtained for the crystalline sample 7. These measurements confirm the complete post synthetic modification and are in agreement with the magnetic measurements reported hereafter which clearly show the presence of two species only for the partially substituted samples.

Temperature dependent magnetic measurements carried out for samples 1, 5-7 are shown in Figure 2 (see ESI for other measurements). For each sample we considered the second thermal cycle, the first one corresponding to the desolvation/'run-in' cycle. The SCO behaviour depends on the synthetic method used (see Scheme SO). In comparison with the parent amino derivative the transition is less cooperative and shifted to lower temperature with $\mathrm{T}_{1 / 2}=278 \mathrm{~K}$ and $287 \mathrm{~K}$ for 5 and 7 , respectively, while a very incomplete conversion is observed for $\mathbf{6}$. In the case of the post synthetic method, the completeness of the transition decrease with the transformation rate (see S12). Such effect is also observed to a lesser extend for sample 7. In fact, although the general chain architecture of the structure is maintained in all samples as demonstrated by the PXRD study, the synthetic approach implemented play a key role on the final spin crossover properties. For sample $\mathbf{5}$, we can suggest that the difficulty to incorporate a bulky moiety on the ligand by the network modifies the inter-chain interactions and steer the molecular network to a specific packing.

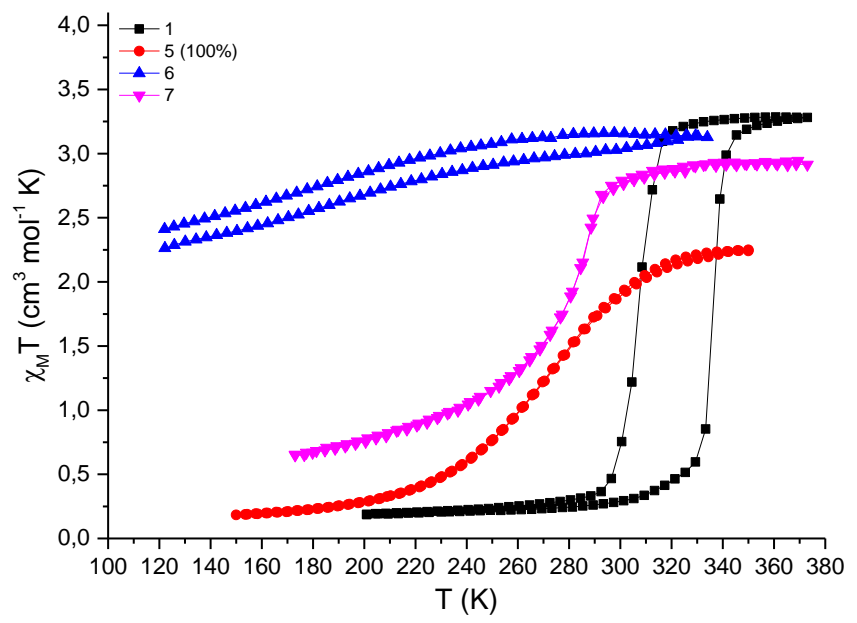

Fig. 2. Magnetic measurements for sample 1, 5, 6 and 7

Regarding the thermal variation of the susceptibility as a function of the degree of transformation (see Fig. S13), it appears that all the intermediate transformations lead to a mixture of two independent complexes. It is interesting to notice that the experiments were repeated twice and led to the same result (same composition and properties for the same experimental conditions). One explanation could be the presence of domains (core of the powder grains) that remains with the same magnetic properties as the starting amino derivative 1 and other growing domains at the surface of the grains that are transformed into the imine derivative. This hypothesis is in agreement with the fact that the starting complex $\mathbf{1}$ is insoluble in our experimental conditions. This trend is totally different compared to that obtained for the direct synthesis in presence of the mixture of ligands (amino and imino ligands). In the latter case, the pace of the SCO curve with only one singularity is consistent with a homogeneous distribution of the imine ligand (see Fig. S14).

In order to deeply probe the composition of the samples, we used Mossbauer spectroscopy and NMR, the latter being rarely used to characterize paramagnetic SCO material. ${ }^{13} \mathrm{C}$ CP-MAS and ${ }^{13} \mathrm{C}$ MAS NMR are two different techniques used to obtain 
the NMR spectra in solid state, while the first is adapted for diamagnetic systems, the latter permits to see also the paramagnetic entities which are associated with faster nuclei relaxation. ${ }^{19,20}$ Indeed, in the ${ }^{13} \mathrm{C}$ CP-MAS at room temperature (Figure 3), we only observe the peak at $155 \mathrm{ppm}$ corresponding to the triazole core for samples 1-4. Although the intensity of the peak seems to be similar due to an increase in the number of scans (in order to be able to observe the peak, see ESI), it decreases from sample 1 to sample 4 in accordance with the increase of the susceptibility measurements. Indeed, from the magnetic behaviour observed in Figure 2 , it is clear that at room temperature (heating mode) $\mathbf{1}$ is diamagnetic, and this character is lost with the degree of transformation (Fig S13), explaining the decrease in intensity of the ${ }^{13} \mathrm{C} C \mathrm{CP}-\mathrm{MAS}$ peak. Moreover, the difficulty to obtain a signal for sample $\mathbf{5}$ is in agreement with a majority HS fraction. In this case, we cannot detect ${ }^{13} \mathrm{C}$ spins in direct vicinity of paramagnetic species, which are certainly severely broadened to be indistinguishable from the baseline. ${ }^{21}$ As expected Sample $\mathbf{6}$ is also silent as it is fully paramagnetic. Mossbauer data were collected for sample $\mathbf{5}$ at 80 and $325 \mathrm{~K}$ and confirmed the residual LS fraction at high temperature suspected by the magnetic measurements (see ESI).

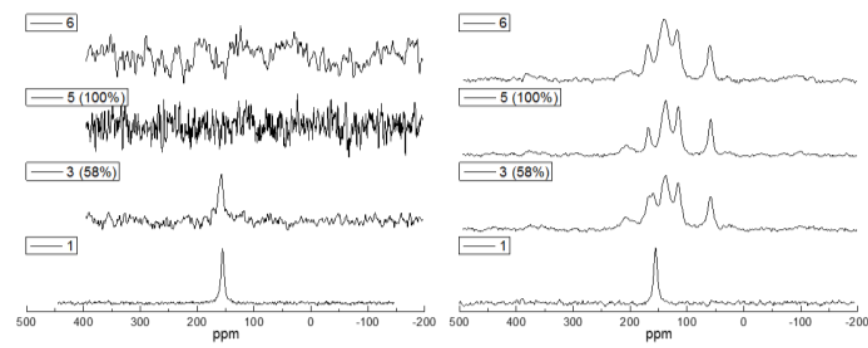

Fig. $3 .{ }^{13} \mathrm{C}$ CP-MAS (left) and ${ }^{13} \mathrm{C}$ MAS (right) NMR spectra for samples $\mathbf{1}, \mathbf{3}, \mathbf{5}$ and $\mathbf{6}$

The ${ }^{13} \mathrm{C}$ MAS NMR (Fig. 3) spectrum at room temperature confirms the diamagnetic entities for 1 while the introduction of the imine ligand lead to the appearance of new peaks at 59 ppm $\left(\mathrm{OCH}_{3}\right), 115$ and $137 \mathrm{ppm}$ (aromatic carbons of $p$ anisaldehyde), $169 \mathrm{ppm}$ (triazole core) and $200 \mathrm{ppm}(\mathrm{CH}=\mathrm{N})$ attributed to the paramagnetic species that increase in intensity in agreement with the degree of transformation. Clearly, in contrast with the ${ }^{13} \mathrm{C}$ CP-MAS experiment, the ${ }^{13} \mathrm{C}$ MAS NMR allows to see the whole system in all cases.

In conclusion, by modifying the reaction time it was possible to obtain a complete post synthetic transformation for a spin crossover complex. The as obtained Schiff base bearing complex presents different spin crossover properties in comparison with those synthesized by direct methods. Of course, whatever the route used, the crystallinity plays a key role on the final behaviour as demonstrated by the comparison of the SCO properties for the two complexes synthesized by different direct methods. Nevertheless, clearly the post synthetic approach leads to specific molecular arrangement and physical properties and then open up the way towards the elaboration of new SCO complexes. The methodology used in this work is currently under investigation to get a synergetic effect between
SCO and different physical or chemical properties that cannot be accessed through the direct synthetic methodology.

\section{Acknowledgements}

A. E.-C. thanks the CONACYT (Mexico) for the postdoctoral grant. We thank Yannick Coppel for the NMR measurements and discussions.

\section{Conflicts of interest}

There are no conflicts to declare.

\section{Notes and references}

G. Molnár, S. Rat, L. Salmon, W. Nicolazzi and A. Bousseksou, Adv. Mater., 2018, 30, 1-23. C. M. Quintero, I. A. Gural'Skiy, L. Salmon, G. Molnár, C. Bergaud and A. Bousseksou, J. Mater. Chem., 2012, 22, 3745-3751. V. Shalabaeva, K. Ridier, S. Rat, M. D. Manrique-Juarez, L. Salmon, I. Séguy, A. Rotaru, G. Molnár and A. Bousseksou, Appl. Phys. Lett., , DOI:10.1063/1.5017458.

J. Dugay, M. Aarts, M. Gimenez-Marqués, T. Kozlova, H. W. Zandbergen, E. Coronado and H. S. J. Van Der Zant, Nano Lett., 2017, 17, 186-193. M. D. Manrique-Juarez, F. Mathieu, V. Shalabaeva, J. Cacheux, S. Rat, L. Nicu, T. Leïchlé, L. Salmon, G. Molnár and A. Bousseksou, Angew. Chemie - Int. Ed., 2017, 56, 8074-8078.

L. Salmon and L. Catala, Comptes Rendus Chim., 2018, 21, 1230-1269.

T. Mallah and M. Cavallini, Comptes Rendus Chim., 2018, 21, 1270-1286.

Z. Yin, S. Wan, J. Yang, M. Kurmoo and M. H. Zeng, Coord. Chem. Rev., 2019, 378, 500-512.

9 S. H. Weisbrod and A. Marx, Chem. Commun., 2008, 56755685.

10 J. E. Clements, J. R. Price, S. M. Neville and C. J. Kepert, Angew. Chemie - Int. Ed., 2014, 53, 10164-10168.

11 C. F. Wang, R. F. Li, X. Y. Chen, R. J. Wei, L. S. Zheng and J. Tao, Angew. Chemie - Int. Ed., 2015, 54, 1574-1577.

12 C. F. Wang, G. Y. Yang, Z. S. Yao and J. Tao, Chem. - A Eur. J., 2018, 24, 3218-3224.

13 Y. Komatsumaru, M. Nakaya, F. Kobayashi, R. Ohtani, M. Nakamura, L. F. Lindoy and S. Hayami, Zeitschrift fur Anorg. und Allg. Chemie, 2018, 644, 729-734.

14 S. Kawabata, S. Chorazy, J. J. Zakrzewski, K. Imoto, T. Fujimoto, K. Nakabayashi, J. Stanek, B. Sieklucka and S. I. Ohkoshi, Inorg. Chem., 2019, 58, 6052-6063.

15 A. Grosjean, N. Daro, S. Pechev, C. Etrillard, G. Chastanet and P. Guionneau, Eur. J. Inorg. Chem., 2018, 2018, 429434.

16 S. Rat, K. Ridier, L. Vendier, G. Molnár, L. Salmon and A. Bousseksou, CrystEngComm, 2017, 19, 3271-3280. M. Piedrahita-Bello, K. Ridier, M. Mikolasek, G. Molnár, W. 
Nicolazzi, L. Salmon and A. Bousseksou, Chem. Commun., 2019, 55, 4769-4772.

A. Grosjean, P. Négrier, P. Bordet, C. Etrillard, D. Mondieig, S. Pechev, E. Lebraud, J. F. Létard and P. Guionneau, Eur. J. Inorg. Chem., 2013, 2, 796-802.

19 M. Bertmer, Solid State Nucl. Magn. Reson., 2017, 81, 1-7.

20 N. P. Wickramasinghe, M. A. Shaibat, C. R. Jones, L. B. Casabianca, A. C. De Dios, J. S. Harwood and Y. Ishii, J. Chem. Phys., , DOI:10.1063/1.2833574.

21 A. V. Kuttatheyil, D. Lässig, J. Lincke, M. Kobalz, M. Baias, K. König, J. Hofmann, H. Krautscheid, C. J. Pickard, J. Haase and M. Bertmer, Inorg. Chem., 2013, 52, 4431-4442. 